\title{
Effect of a Specific Exercise Program on Spinal and Joints Stiffness for Patients with Ankylosing Spondylitis
}

\author{
Wafaa Ramadan Ahmed ${ }^{1}$, Sahra Zaki Azer ${ }^{2}$, Eman Mawed Fahem ${ }^{3}$ \& Safaa Ali Mahran ${ }^{4}$ \\ 1. Lecturer of Medical-Surgical Nursing, Faculty of Nursing, Assiut University, Egypt. \\ 2. Assistant Professor of Medical-Surgical Nursing, Faculty of Nursing, Assiut University, Egypt. \\ 3. Lecturer of Medical-Surgical Nursing, Faculty of Nursing, BeniSuif University, Egypt. \\ 4. Assistant professor of Rheumatology and Rehabilitation, Faculty of Medicine, Assiut University, Egypt
}

\begin{abstract}
:
Regular exercises are of fundamental importance in the successful long-term management of Ankylosing Spondylitis. The current study aimed to evaluate the effect of a specific exercise program on spinal and joints stiffness for patients with Ankylosing Spondylitis. Design: Quasi experimental research design was utilized. Subjects: Random sample of adult patients (30), male and female, their age ranging from 20 - 60 years old. Setting: Rheumatology and rehabilitation department and outpatients' clinics at Assiut University Hospital. Tools: Interview Questionnaire consisted of four parts; patient assessment, Bath Ankylosing Spondylitis Functional Index, Health assessment Questionnaire for spondyloarthropathies, and Bath Ankylosing Spondylitis Metrology Index. Results: statistically significant difference between pre and post-test mean score of bath ankylosing spondylitis functional index $(66.66 \pm 6.29$ and $37.66 \pm 4.78)$ respectively with $\mathrm{p}$. value $(0.0001)$, health assessment questionnaire for spondyloarthropathies $(45.333 \pm 9.20$ pre versus $22.066 \pm 2.148$ post) with p. value $(0.006)$, and bath ankylosing spondylitis metrology index with pre and post-test mean score $(4.640 \pm 0.870$ and $1.413 \pm 0.319)$ respectively with $\mathrm{p}$. value $(\mathrm{p}=0.0001)$.Conclusion: the specific exercise program has a valuable effect on patients with Ankylosing Spondylitis on their physical function, and stiffness (mobility of the axial skeleton). Recommendations; Applying the specific exercise program on the patients with Ankylosing Spondylitis at different rehabilitation units to decrease the spinal and joint stiffness.
\end{abstract}

\section{Keywords: Ankylosing Spondylitis, Exercise Program, Joints, Spinal \& Stiffness.}

\section{Introduction}

Ankylosing spondylitis (AS) is a chronic inflammation of the spine and sacroiliac joints caused by a form of progressive arthritis. It can also affect other joints and organs in the body, such as the eyes, lungs, kidneys, shoulders, knees, hips, heart, and ankles. However, AS primarily affects the axial skeleton, including the ligaments and joints (Conditions, 2021).

The cause of AS is not yet fully known, but there is an important genetic element; most people with AS have a gene called HLA-B27. In people with AS this gene is found in over $90 \%$ of northern Europeans, about $80 \%$ of Mediterranean people, and about $50 \%$ of African Americans. Many genes are involved, not just HLA-B27. The search is now on for these additional genes and also for the trigger factor (possibly a bacterial infection) that starts the disease processes (Yazici et al, 2020).

AS is most often diagnosed in adults under the age of 40 , with about $80 \%$ of patients experiencing their first symptoms by the age of 30 . Patients above the age of 45 make up less than 5\% of all patients. Men are more likely than women to have AS. Relatives of people who have been diagnosed with cancer are at a higher risk (Wang and Ward, 2018).

AS usually starts with chronic low back pain and stiffness which is gradual and insidious in onset. It can take a long time, on average about 6 years, before the correct diagnosis is made. AS results in gradually progressive stiffness and limitations of spinal mobility and also restricted the expansion of the chest. In some people AS can affect other joints besides the spine, in particular the hip and shoulder joints. Involvement of these and other limb joints is more common in some developing countries, especially when the disease starts in childhood (Physiopedia, 2021).

Acute anterior uveitis, aortic incompetence, coronary conduction abnormalities, fibrosis of the upper lobes of the lungs, neurologic involvement, and secondary renal amyloidosis are all extra skeletal forms of the disorder. AS is linked to a significant financial and social burden on both the patient and community (Amarnani, \& Soni, 2020).

Most cases of AS can be diagnosed, or at least initially suspected, based on a good medical history and clinical examination. The back pain of early AS is usually a dull ache that is difficult to localize, felt 
deep in the buttock or lower back, it may be associated with muscle spasms and tenderness in the back. The symptoms are typically worse on waking up in the morning ('morning stiffness') because a long period of inactivity usually makes the pain and stiffness worse. It may even be bad enough to wake the patient up at night sometimes (Elia, 2018).

A significant percentage of patients have spinal osteoporosis, which can lead to vertebral fractures and thoracic kyphosis, lowering their quality of life. The effect of AS on the workplace can be seen in a variety of ways, from needing assistance at work to leaving the workforce. Patients with AS often have a huge effect on health-care and non-health-care services (Firestein, et al, 2017).

Treatment goals should focus on relieving pain and stiffness, maintaining axial spine motion and functional ability, and preventing spinal complications. Non-pharmacologic interventions should include regular exercise, postural training, and physical therapy. First-line medication therapy is with long-term, daily non-steroidal anti-inflammatory drugs (NSAIDs). Should NSAIDs not provide adequate relief, they can be combined with or substituted for tumor necrosis factor inhibitors (TNFIs) such as adalimumab, infliximab, or etanercept (Wenker \& Quint, 2021).

Local steroid injections can be considered instead of systemic glucocorticoids. According to the patient's clinical image, possible symptoms, and/or extraarticular presentations of the condition, expert referrals may be necessary. Dermatologists, ophthalmologists, and gastroenterologists may assist with non-musculoskeletal effects of AS, whereas rheumatologists can help with a specific diagnosis, treatment, and supervision (Liang et al, 2018).

It is necessary to exercise or move about for a few minutes before going back to bed. Physical activity or a hot shower helps minimize back pain and stiffness, and exposure to cold or dampness may make the symptoms worse. Occasionally, many people may complain that they get fatigued easily (Wenker, \& Quint, 2021). Regular exercises are of fundamental importance in the successful long-term management of AS. They assist in the preservation or enhancement of balance, chest extension, and spinal mobility, as well as the avoidance or reduction of deformity. Recreational exercise relieves discomfort and stiffness, and back exercise increases muscle function and relieves pain (Millner et al, 2016).

\section{Significance of the study:}

Ankylosing Spondylitis (AS) typically affects young people, beginning between the ages of 15 and 30years old. The average age of onset of the disease is 24 years old which is the age of work and productivity
(Hollick et al, 2019). The impact of AS can be seen in various aspects of employment, ranging from requiring assistance at work to withdrawal from the workforce which increases the economic burden on the country. This research helped the patients to minimize the complications associated with the disease by reducing Spinal and Joints Stiffness for Patients with Ankylosing Spondylitis.

Aim of the study:

The study aimed to evaluate the effect of a specific exercise program on spinal and joints stiffness for patients with Ankylosing Spondylitis.

\section{Research Hypotheses:}

Patients with Ankylosing Spondylitis in the study after receiving a specific exercise program will experience less spinal and joint stiffness than before.

\section{Research design:}

Quasi experimental (pre/ post-test) research design was utilized to conduct this study.

\section{Setting:}

The study was conducted in the Rheumatology and rehabilitation department and outpatients' clinic at Assiut University Hospital.

\section{Sample:}

A selected sample of (30) adult patients, male and female, their ages ranging from 20 - 60 years old, diagnosed with Ankylosing spondylitis at least two years before.

Exclusion criteria: Patients who have other rheumatologic diseases, advanced Ankylosing stages, having any spinal \& joint deformities or end-organ failure were excluded from this study.

The sample size was determined by using power analysis according to the patients flow with precision levels $5 \%$ at confidence level $95 \%$ and $p<.05$.

Tools of the study:

Tool I: Patients' Interview Questionnaire: it included four parts:

Part 1: Patient assessment: this part was developed by the researchers based on recent review of literatures and included (demographic data, chronic diseases assessment, health habits, and previous family member history of the disease).

Part II: Bath Ankylosing Spondylitis Functional Index (BASFI): it was developed by (Calin et al; 1994) to define and monitor physical functioning of patients with ankylosing spondylitis (AS).

\section{Scoring System:}

- BASFI is a visual analog scale (VAS) index, whereby the patient rates his/her ability to perform tasks (BASFI) by marking a vertical line on a 100 $\mathrm{mm}$ horizontal line which are scored with a rating scale from 0 (no functional impairments) to 10 (maximal impairment) It consists of ten task lines 
to assess the degree of difficulty of performing each task

- The tasks are: (1) putting on socks, (2) bending forward to pick up a pen, (3) reaching a high shelf, (4) getting up from an armless chair, (5) getting up from the floor from lying supine, (6) standing unsupported, (7) climbing steps without a handrail, (8) looking over their shoulders, (9) performing physically demanding activities, and (10) doing a full day's activities.

- The total BASFI score is calculated by adding all ten scores. Higher scores reflect worse functions.

Part III: Health assessment Questionnaire for spondyloarthropathies (HAQ -S): it was developed by (Daltroy et al; 1990) to assess the physical functioning of an individual with Ankylosing spondylitis (AS). The measure includes items concerning dressing, arising, eating, walking, hygiene, reaching, gripping, and errands and chores taken from the disability index (DI) of the HAQ, and an additional 5 specific items concerning neck function and static posture (driving a car, using a rear-vision mirror, carrying heavy groceries, sitting for long periods, and working at a desk).

\section{Scoring System:}

- The scale provides four answers categorizes to the question $0=$ without any difficulty, $1=$ with some difficulty, and $2=$ with much difficulty, and $3=$ unable to do.

- The total score ranges from 0 to 60 . Higher scores reflect more difficulty to perform the physical function.

Part VI: Bath Ankylosing Spondylitis Metrology Index (BASMI): it was developed by (Jenkinson et al; 1994). Health care professionals who have been qualified to conduct the clinical assessments needed to calculate the axial skeleton's mobility in patients with ankylosing spondylitis (AS) and enable reliable appraisal of clinically relevant differences in spinal movement perform the measurements (measure the degree of spinal and joint stiffness).

The BASMI is reliable, repeatable, and simple to use with little preparation, providing useful knowledge about spinal mobility due to inflammation or structural damage. The BASMI is well-suited for use in clinical trials because it is adaptive enough to distinguish differences within patient groups and provides additional insight not available from other outcome tests. It is an appropriate measure for assessing the effect of interventions in patients with AS and spondyloarthritis. BASMI consists of a combined index to assess the patient's spinal mobility (lateral lumbar flexion, tragus-to-wall distance, lumbar flexion (modified Schober), maximal intermalleolar distance, and cervical rotation.

\section{Scoring System:}

- Each item is scored from $0-10$ based on individually defined cut points. Ranges are given as cervical rotation $\left(>85.0^{\circ}\right.$ to $\left.\leq 8.5^{\circ}\right)$, tragus to the wall $(<10 \mathrm{~cm}$ to $\geq 38 \mathrm{~cm})$, lumbar flexion $(>7.0 \mathrm{~cm}$ to $\leq 0.7 \mathrm{~cm})$, lumbar side flexion $(>20.0 \mathrm{~cm}$ to $<1.2 \mathrm{~cm})$, and intermalleolar distance $(\geq 120 \mathrm{~cm}$ to $<30 \mathrm{~cm}$ ).

- Measurements derived from the clinical exam and referred to BASMI to calculate a score $(0-10)$ for the 5 measures.

- Add these together and divide by 5 to obtain BASMI. BASMI gives a final score between 0 and 10 , where a higher score reflects a more significant impairment of spinal mobility (stiffness) ; The higher the BASMI score the more severe the patient's limitation of movement due to their AS.

Specific exercise program for patients with Ankylosing Spondylitis:

Based on Patients needs assessment, the researchers developed a specific exercise program according to the literature review and available resources, consisted of three parts:

Part (I): Information about the definition of Ankylosing spondylitis, causes, manifestations, diagnosis, and treatment.

Part (II): specific exercises for neck, arms, shoulders, back, trunk, pelvic, lower limbs, and breathing exercises.

Neck exercises: sit on a chair or stand erect, turn the head right and keep it on for 15 seconds, rotate the left head and keep it on for 15 seconds, tilt the head left and right. Touch the left and right shoulder for 15 seconds at a time; repeat the previous steps 2-4 times for each direction.

Arms exercises: sleep on the back with the knees bent, raise the arms up to the level of the head while maintaining position for 15 seconds, return the arms back to the ground level while maintaining position for 15 seconds, and repeat the exercise 2-4 times.

Shoulder exercises: sit on a chair or stand upright, lift the hands above the head level while taking a deep breath, breathe naturally while maintaining this position for 15 seconds, and return to the starting point and repeat this exercise 2-4 times.

Back Exercises: in a crawling position, exhale with curving back for 15 seconds, inhale with curving back inside for 15 seconds, and repeat the exercise 2-4 times.

Trunk exercises: (The body is well stretched, the abdomen touches the ground and the upper part is lifted by the elbows, to maintain the same position for 15 seconds; patient can read or watch TV during this period, body stretched on the back with 
two knees bent, holds the pelvis and keeps the body based on the foot and shoulders, keep this position for 15 seconds). Also, (sit on the knees with the arms placed on the chest, rotate the trunk right and north 15-15 seconds, repeat exercise 2-4 times) or, (sit on the knees with arms on both sides of the body, bend the trunk left and right until touch the ground with fingertips, maintain this position for 15 seconds and repeat this exercise 2-4 times).

Pelvic exercises: (sit on the floor with extended legs; flex the left leg while keeping the right leg extended for 15 seconds. Repeat the previous exercise with the right leg, repeat the exercise 2-4 times), or (sleep on the ground with extended legs, and flex the left leg while keeping the right leg extended for 15 seconds, repeat the previous exercise with the right leg, and repeat the exercise 2-4 times).

Exercises of the lower limbs: (sit on the knees and flex the right leg, maintain the position for 15 seconds, Repeat the exercise with the left leg, Repeat the exercise 2-4 times). Also, (sleep on the ground with the legs extended; flex the left leg, elevate the right leg with keeping it extended with a wrapped towel for 15 seconds. Repeat the previous exercise with the right leg, and repeat the exercise 2-4 times).

Breathing exercises: This exercise is performed by sitting or standing positions with one hand on the abdomen and the other on the chest, take a deep breath from the nose until the chest expands and is filled with enough air to hold it for a long period of time or for 10 seconds, and then exhale it from the mouth, Repeat the process for 10 minutes.

Part (3): Information and teaching tips about correct postures during activity daily livings as (Prone Lying, back against the wall, Posture during sitting, Posture during lifting items, Posture in the kitchen, and Posture during using the computer).

Prone Lying: Lie face down on a firm surface for 20 minutes daily. If unable to lie flat, place a pillow under the chest and a towel under the forehead.

Back against the wall: Stand against a wall. Place the heels 4 inches away from the wall. The buttocks and shoulders should be as close to the wall as possible. Hold this position for 5 seconds and repeat 3 times daily.

Sitting position: Adjust the height of the chair according to the height of the work area, Ensure the shoulders are relaxed and without strain (shoulders back, ribs in), Where possible, ensure the chair supports the natural curve of the spine, Do stretching and relaxation exercises for five minutes every hour

Position during lifting items: while lifting objects, bend the knee to keep the back straight while avoiding bending the back or twisting while lifting objects. Avoid sudden movements and do not lift heavy objects alone. It is better to pull items than lift them.

Posture in the kitchen: Work surfaces should be high enough to avoid bending over. If the surface can't be raised, sit down, Keep items that are often used such as food, pots and pans within easy reach at waist height, sit on a high chair when cooking, preparing food or washing up, and If the cooker is low, make sure to bend the knees and hips, not the back.

Posture during using computer: maintain good posture when working at the keyboard. The back curves should be maintained with the use of a chair with a back support, keep the feet supported either on the floor or on a footrest, avoids twisting or turning the trunk or neck when working. Keep the shoulders relaxed with elbows close to the sides when working, avoid resting the elbows on the hard surface or edge of the table, elbows should be positioned 100 or 110 degrees, and the wrists should be in neutral position when keying or using a mobile device.

\section{Fieldwork description:}

Validity and Reliability of the study tools:

- BASFI reliability: test-retest showed stability between time 1 and time 3, with Pearson's correlation coefficient given as $r=0.92$.

- Health assessment Questionnaire for spondyloarthropathies internal consistency is excellent, with Cronbach's $\alpha$ reported at 0.936

- BASMI reliability has been shown to be good; cervical rotation $(r=0.98)$, tragus to wall $(r=0.99)$, lumbar side flexion $(r=0.94)$, lumbar flexion as measured by the modified Schober's method ( $\mathrm{r}=$ $0.99)$, and intermalleolar distance $(r=0.98)$.

- Content validity of the specific exercise program was checked by panel of 5 experts ( 3 professors in fields of rheumatology and rehabilitation and 2 professors in nursing) who reviewed the exercise program for clarity, relevance, comprehensiveness, understanding, and easiness for application. Minor modifications were required, correction was carried out accordingly.

\section{Ethical considerations:}

All research ethics principles were fulfilled according to the World Medical Association Declaration of Helsinki (1997). Before the conduction of the pilot study as well as the actual study, official permission and consent were obtained from the dean of the Faculty of Nursing, as well as the director of the Rheumatology department and outpatients' clinic after explaining the nature and purpose of the study. The subject of the study is entitled to refuse to participate and/or withdraw from the study at any time without any reason. During data collection, the research topic 
of privacy was not considered to pose any health hazards. Participants were assured of being highly confidential with all their data.

\section{Pilot study:}

A pilot study was done on $10 \%$ (3 patients.) of the sample to test the clarity and feasibility of the developed tools. Also, it provided an estimate of the time needed to fill out the tools. There were minimal modifications, so the pilot study sample was excluded from the whole study sample and new patients ate selected to replace the excluded patients of pilot study.

\section{Methods:}

The study proceeded using the following phases:

\section{Preparatory phase:}

- Official permission was obtained from the head of the Rheumatology and rehabilitation department and outpatients' clinics at Assiut University Hospital to conduct the study.

- Oral consent was taken from patients who were agreeing to participate after reassured about the confidentiality and the information will be used for the purposeful research.

- Baseline data were collected by researchers using tools (I).

\section{Implementation phase:}

- Data were collected during the period from first of November 2017 to end of January 2019, during morning and afternoon shifts at the Rheumatology and rehabilitation department and outpatient clinic at Assiut university hospital.

- Each patient was interviewed individually by the researcher; the number of interviews per day 3 patients at the day. The average time taken for filling the sheet was around $20-30$ minutes depending on the response and cooperation of the patients.

- The aim of the study was explained to the patients before starting data collection. Patients also informed about what will be done for them.

- The researcher provided the selected patients with the specific exercise program by dividing the program into four sessions

The $1^{\text {st }}$ session; information about the definition of Ankylosing spondylitis, causes, manifestations, diagnosis, and treatment. The time needed for the first session was $10-15$ minutes.

In the $\mathbf{2}^{\text {nd }}$ session; teach the patients a specific exercise for the neck, arms, and shoulders. The time needed for the second session was $20-30$ minutes.

The 3rd session: teach the patients a specific exercise for back, trunk, pelvic, lower limbs, and breathing exercises. The time needed for the third session was 20 -30 minutes.
The 4th session; teach the patients tips for a successful way for performing the daily activities as the proper posture while lying prone, standing against the wall, proper sitting position, the correct way for lifting an object, proper position while standing and moving in the kitchen, and proper posture during using the computer. The time needed for the third session was 25 - 35 minutes.

- The studied patients were given an educational colored booklet in clear Arabic language. The researcher used pictures, diagrams, and role-play to help them retain the learned material then gives them a copy of the illustrated booklet.

- The patients were permitted to perform the learned exercises under the researcher's guidance to ensure that the patients gain the exact method of applying the exercise correctly.

- Patients are scheduled to perform the prescribed exercised under the researchers' guidance three days a week.

- The session took approximately 20-30 minutes in the previously mentioned setting.

- The researchers encourage the patients to perform the learned exercise regularly without dropping the exercise sessions.

- The patients were followed after discharge from the department in the outpatients' clinic at Assuit University Hospital to complete the exercise sessions.

- A scheduled follow-up meeting (after 12 weeks from starting the program) was arranged by the researchers to evaluate the effect of the specific exercise program.

\section{Evaluation phase}

In this phase, the studied patients were reassessed after 12 weeks using (tools I, parts II, III, and IV) to evaluate the effect of implementing the specific exercise program on spinal and joints stiffness for patients with Ankylosing Spondylitis.

\section{Statistical design:}

Statistical analysis all the analyses were performed using SPSS (IBM version 22.0). To analyze the general data of subjects the researchers used descriptive statistics and constituent ratio. The researchers utilized the Pearson chi-square and the paired t-tests to analyze the study results. All p. values were two-tailed, and the significance level was considered $<0.05$. 


\section{Results:}

Table (1): Distribution of the demographic characteristics of the studied patients $(n=30)$ :

\begin{tabular}{|c|c|c|}
\hline Demographic characteristics & No. & $\%$ \\
\hline $\begin{array}{l}\text { Age group } \\
18:<30 \text { yrs } \\
30:<45 \text { yrs } \\
45: 65 \mathrm{yrs}\end{array}$ & $\begin{array}{c}6 \\
20 \\
4\end{array}$ & $\begin{array}{l}20.0 \\
\mathbf{6 6 . 7} \\
13.3\end{array}$ \\
\hline Age (mean) & $37.80 \pm 7.906$ years & \\
\hline $\begin{array}{l}\text { Sex } \\
\text { Male } \\
\text { Female }\end{array}$ & $\begin{array}{l}18 \\
12\end{array}$ & $\begin{array}{l}\mathbf{6 0} \\
40\end{array}$ \\
\hline $\begin{array}{l}\text { Marital status } \\
\text { Single } \\
\text { Married }\end{array}$ & $\begin{array}{c}6 \\
24\end{array}$ & $\begin{array}{l}20 \\
\mathbf{8 0}\end{array}$ \\
\hline $\begin{array}{l}\text { Educational level } \\
\text { Illiterate } \\
\text { Read and write } \\
\text { Primary } \\
\text { Preparatory } \\
\text { Secondary } \\
\text { University } \\
\end{array}$ & $\begin{array}{l}4 \\
6 \\
4 \\
6 \\
4 \\
6 \\
\end{array}$ & $\begin{array}{l}13.3 \\
\mathbf{2 0 . 0} \\
13.3 \\
\mathbf{2 0 . 0} \\
13.4 \\
\mathbf{2 0 . 0}\end{array}$ \\
\hline $\begin{array}{l}\text { Occupation } \\
\text { Housewives } \\
\text { Farmer } \\
\text { Hospital member } \\
\text { Craft worker }\end{array}$ & $\begin{array}{c}4 \\
10 \\
4 \\
12\end{array}$ & $\begin{array}{l}13.3 \\
33.4 \\
13.3 \\
\mathbf{4 0 . 0}\end{array}$ \\
\hline $\begin{array}{l}\text { BMI } \\
\text { Standard } \\
\text { Overweight } \\
\text { Obese } \\
\end{array}$ & $\begin{array}{c}10 \\
8 \\
12 \\
\end{array}$ & $\begin{array}{l}33.3 \\
26.7 \\
\mathbf{4 0 . 0}\end{array}$ \\
\hline $\begin{array}{l}\text { Previous family history } \\
\text { Yes } \\
\text { No }\end{array}$ & $\begin{array}{l}14 \\
16\end{array}$ & $\begin{array}{l}46.7 \\
\mathbf{5 3 . 3}\end{array}$ \\
\hline
\end{tabular}

Table (2): Distribution of chronic diseases, health habits, and previous family member history of the disease among the studied patients $(n=30)$ :

\begin{tabular}{|c|c|c|c|c|}
\hline \multirow{2}{*}{ Items } & \multicolumn{2}{|c|}{ Present } & \multicolumn{2}{c|}{ Absent } \\
\cline { 2 - 5 } Chronic diseases & No & \% & No & \% \\
\hline- DM & & & & \\
\hline- HTN & 16 & $\mathbf{5 3 . 3}$ & 14 & 46.7 \\
\hline$-\quad$ Pulmonary & 6 & 20 & 24 & 80 \\
\hline Health habits & 8 & 26.7 & 22 & 73.3 \\
\hline- Tea and coffee drinking & & & & \\
\hline$-\quad$ Smoking & 24 & $\mathbf{8 0}$ & 6 & 20 \\
\hline$-\quad$ Physical activity & 10 & 33.3 & 20 & 66.7 \\
\hline
\end{tabular}

Table (3): Distribution of Bath Ankylosing Spondylitis Functional Index (BASFI) of the studied patients $(\mathbf{n}=\mathbf{3 0})$ :

\begin{tabular}{|l|c|c|c|}
\hline \multicolumn{1}{|c|}{ BASFI } & $\begin{array}{c}\text { Mean } \pm \text { SD } \\
\text { (Score from 0-100) }\end{array}$ & Minimum score & Maximum score \\
\hline Pretest & $66.66 \pm 6.29$ & 64.314 & 69.018 \\
\hline Post-test & $37.66 \pm 4.78$ & 35.881 & 39.451 \\
\hline Significance test & \multicolumn{2}{|c|}{$p=\mathbf{0 . 0 0 0 1} * * \quad \mathbf{t}=\mathbf{3 0 . 8 6 6}$} \\
\hline
\end{tabular}

Paired t test, significance considered if $p<0.05$ 
Table (4): Distribution of Health assessment Questionnaire for spondyloarthropathies (HAQ -S) of the studied patients (Score from 0-60):

\begin{tabular}{|c|c|c|c|}
\hline HAQ $-\mathbf{S}$ & Mean $\mathbf{\pm}$ SD & Minimum score & Maximum score \\
\hline Pretest & $45.333 \pm 9.20$ & 41.897 & 48.768 \\
\hline Post-test & $22.066 \pm 2.148$ & 21.264 & 22.868 \\
\hline Significance test & \multicolumn{3}{|c|}{$\mathbf{p = 0 . 0 0 6} * \mathbf{t}=\mathbf{1 5 . 2 3 2}$} \\
\hline
\end{tabular}

Paired t test, significance considered if $p<0.05$

Table (5): Distribution of Bath Ankylosing Spondylitis Metrology Index (BASMI) of the studied patients (Score from 0- 10):

\begin{tabular}{|c|c|c|c|}
\hline BASMI & Mean \pm SD & Minimum score & Maximum score \\
\hline Pretest & $4.640 \pm 0.870$ & 4.315 & 4.964 \\
\hline Post-test & $1.413 \pm 0.319$ & 1.294 & 1.532 \\
\hline Significance test & \multicolumn{3}{|c|}{$\mathrm{p}=0.0001 * * \quad \mathrm{t}=22.496$} \\
\hline
\end{tabular}

Paired t-test, significance considered if $p<0.05$

Table (6): Relation between the pre \& post-test mean scores of BASFI, BASMI, and health assessment questionnaire for spondyloarthropathies and body mass index (BMI) of the studied patients (30).

\begin{tabular}{|l|c|c|c|c|c|c|}
\hline $\begin{array}{c}\text { BMI } \\
\text { categories }\end{array}$ & $\begin{array}{c}\text { BASFI } \\
\text { Mean } \pm \text { SD } \\
\text { Pretest }\end{array}$ & $\begin{array}{c}\text { BASFI } \\
\text { Mean } \pm \text { SD } \\
\text { post-test }\end{array}$ & $\begin{array}{c}\text { BASMI } \\
\text { Mean } \pm \text { SD } \\
\text { Pretest }\end{array}$ & $\begin{array}{c}\text { BASMI } \\
\text { Mean } \pm \text { SD } \\
\text { post-test }\end{array}$ & $\begin{array}{c}\text { Health } \\
\text { assessment } \\
\text { Mean } \pm \text { SD } \\
\text { Pretest }\end{array}$ & $\begin{array}{c}\text { Health } \\
\text { assessment } \\
\text { Mean } \pm \text { SD } \\
\text { post-test }\end{array}$ \\
\hline Standard & $69.80 \pm 7.583$ & $37.400 \pm 3.977$ & $4.840 \pm 1.094$ & $1.480 \pm 0.367$ & $48.400 \pm 13.426$ & $24.800 \pm 1.032$ \\
Overweight & $66.25 \pm 5.775$ & $37.500 \pm 1.195$ & $4.400 \pm 1.014$ & $1.300 \pm 0.385$ & $45.000 \pm 6.414$ & $21.000 \pm 1.069$ \\
Obese & $64.33 \pm 4.618$ & $38.000 \pm 6.795$ & $4.633 \pm 0.531$ & $1.433 \pm 0.222$ & $43.000 \pm 5.908$ & $20.500 \pm 0.522$ \\
\hline Significance & $\mathrm{F}=2.258$ & $\mathrm{~F}=0.046$ & $\mathrm{~F}=0.551$ & $\mathrm{~F}=0.732$ & $\mathrm{~F}=0.943$ & $\mathrm{~F}=74.228$ \\
& $p=0.124$ & $p=0.955$ & $p=0.583$ & $p=0.490$ & $p=0.402$ & $p=\mathbf{0 . 0 0 0 1} * *$ \\
\hline
\end{tabular}

One way ANOVA test was used, significance if the p-value is less than 0.05

Table (7): Correlations between the mean scores of BASMI, BASFI, and health assessment questionnaire for spondyloarthropathies of the studied patients (30).

\begin{tabular}{|l|c|c|c|}
\hline \multicolumn{1}{|c|}{ Variables } & & P & R \\
\hline BASMI & Pre \& post test & $0.016^{*}$ & 0.435 \\
\hline BASFI & Pre \& post test & $0.0001^{* *}$ & 0.599 \\
\hline $\begin{array}{l}\text { Health assessment Questionnaire for } \\
\text { spondyloarthropathies }\end{array}$ & Pre \& post test & $0.006^{*}$ & 0.487 \\
\hline \multirow{2}{*}{ BASMI \& BASFI } & Pre test & 0.088 & $0.317-$ \\
\cline { 2 - 4 } & Post-test & 0.526 & 0.121 \\
\hline \multirow{2}{*}{ BASMI \& Health assessment } & Pre-test & 0.387 & $0.164-$ \\
\cline { 2 - 4 } & Post-test & 0.994 & $0.001-$ \\
\hline \multirow{2}{*}{ BASFI \& health assessment } & Pre-test & 0.220 & 0.231 \\
\cline { 2 - 4 } & Post-test & $0.0001^{* *}$ & 0.668 \\
\hline
\end{tabular}

Table (1): Shows that two-thirds $(66.7 \%)$ of study patients their age ranging from 30to less than 45years old with a mean age (37.80 \pm 7.906 years). More than half of the study patients were male, married $(80 \%)$. Regarding the educational level, sixty percent of patients are read and write, preparatory and university education with $20 \%$ for each category). More than one-third of patients (40\%) were craft workers and obese. Finally, nearly half of the patients (46.7\%) have a previous family history of the disease.
Table (2): Shows that more than half of patients $(53.3 \%)$ have diabetes mellitus, the majority of them $(80 \%)$ consume tea and coffee, and $(86.7 \%)$ perform physical activity.

Table (3): Shows that there was a statistically significant difference between pre and post-test mean score of bath ankylosing spondylitis functional index with p. value $\left(0.0001^{* *}\right)$ which means that; the patient's physical functioning has been improved after three months of exercise programs. 
Table (4): Shows that there was a statistically significant difference between pre and post-test mean score of the health assessment questionnaire for spondyloarthropathies with a p. value $\left(0.006^{*}\right)$ which means that; the patient's difficulty of performing the physical functioning has been decreased after three months from implementing of the exercise program.

Table (5): Shows that there was a statistically significant difference between pre, and post-test mean score of baths ankylosing spondylitis metrology index with p. value $(0.0001 * *)$ which means that; the patient's functional ability in the spinal column (axial status) has been improved after three months from implementing of the exercise program.

Table (6): Clarify that there was a statistically significant difference between the mean score of the health assessment questionnaire for spondyloarthropathies (post-test) and BMI of the studied sample.

Table (7): Shows that there were statistical significant differences between pre and post test scores regarding BASMI, BASFI, and Health assessment questionnaire for spondyloarthropathies which means that the specific exercise program has a great effect on improving the patients' condition (physical function \& mobility and reducing stiffness). Also, there was a positive correlation between BASFI $\&$ health assessment questionnaire for spondyloarthropathies (post-test) which reflects that as the patients' physical improved, the patients' ability to perform activities as concerning dressing, arising, eating, walking, hygiene, reaching, gripping, and errands and chores that measured by health assessment questionnaire for spondyloarthropathies will be improved as well.

\section{Discussion:}

Ankylosing spondylitis, (AS) is a chronic, inflammatory, and progressive rheumatic condition characterized by back pain, decreased mobility, and deformity, as well as weakness and poor quality of life (Fongen et al., 2013).

Exercise, in combination with pharmacological treatment, is considered a critical method in the management of ankylosing spondylitis (AS) and has greatly increased the control of signs and symptoms of this challenging disease since the initiation of biological therapy (Jung et al., 2019).

Ankylosing spondylitis affected the third and fourth decades of patients' age with a mean age (37.80 \pm 7.906 years). More than half of the study patients were male, married. This result becomes within the identical line with Johns Hopkins Arthritis Center, (2021) as reported that "Men are more likely than women to develop AS. In most cases, illness onset occurs in the second and third decades of life. More than eighty percent of patients with AS reports symptoms at less than or equal thirty years of age, while only five percent can emerge with symptoms at more than or equal forty five years of age". Also, Fang et al., (2019) reported that the age of patients was more than or equal twenty years old. More than three-thirds of the studied samples were males. In contrast to our study finding Gossec et al., (2019) and Rouse et al., (2019) revealed that two-thirds of the study samples' age more than forty years and were females. Also, Regnaux et al., (2019) reported that most participants were male; the median age was forty five years old years old.

Regarding patient's medical data, the current study revealed that more than half of patients have diabetes mellitus, and nearly half of patients have a previous family history of the disease. Jin et al, (2017) were agreeing with the present study findings as they revealed that "Patients with AS and spondyloarthritis have an increased risk of developing T2DM".Also, Lee \& Song, (2019) reported that" Ankylosing spondylitis patients had a twenty one-fold higher average rate of diabetes mellitus than non-ankylosing spondylitis patients, according to a national cohort report". Additionally, Feintuch, (2021) \& Naqvi, (2021) reported that "If parents or siblings have ankylosing spondylitis, it's estimated that patients are ten to twenty times more likely to have ankylosing spondylitis than someone with no family history".

The present study revealed that, there was a statistically significant difference between pre and post-test mean score of bath ankylosing spondylitis functional index (BASFI) which means that; the patient's physical functioning has been improved after three months from implementing of the exercise program. From the researchers' point of view, it was an acceptable result as the specific exercise program provided to patients contributed to improving the patients' joint movement and flexibility which reflects on their physical functioning.

These results are in the same line with Gyurcsik et al., (2013) who reported that the exercise program was conducted individually during the first four weeks and in small groups during the following 8 weeks, when the patient assessment of disease activity and pain intensity, BASFI significantly improved after the physical therapy program.

Also, Regnaux et al., (2019) found that, the most frequently used exercises were those designed to help improve strength, flexibility, stretching, and breathing. While Liang et al., (2015) mentioned that" compared patients who did a five-times-per-week home-based fitness program; tests were done by the same clinician at baseline and three months later. A statistically significant improvement was observed in 
pain and Bath Ankylosing Spondylitis Functional Index (BASFI)".

According to the present study findings, there was a statistically significant difference between pre, and post-test mean score of the health assessment questionnaire for spondyloarthropathies which means that; the patient's difficulty of performing the physical functioning has been decreased after three months of exercise programs. According to the researchers' opinion these results were expected as after providing patients a three months specific exercise program, patients' joint movement and flexibility were improved as measured by BASMI, which reflected on the patients' physical functioning and daily activities.

Annelie et al., (2020)finding agree with the present study results as they stated that, Exercise and rehabilitation intervention services have been found to help patients with AS control their disease activity and preserve or improve their spinal function and physical activity. Also, Gyurcsik et al., (2012) \& Peter et al., (2019)claimed that, in a group of ten participants, a complex physical therapy regimen resulted in discomfort and spine tension reduction, as well as changes in many subjective and functional criteria when compared to the baseline assessment.

Pécourneau et al., (2018) were disagree with the present study finding and reported that" Physical therapy, according to the current meta-analysis, has a minor benefit and was thus preferable to alternative activities in terms of improving disability and involvement limits in patients with AS." This result may have been obtained as a result of the evaluation and formulation of physical therapy after the treatment of patients with AS.

According to the present study findings, there was a statistically significant difference between pre, and post-test mean score of baths ankylosing spondylitis metrology index which means that; the patient's functional ability of the spinal column (axial status) which has been improved after three months of exercise program. According to the researchers' opinion, it was an accurate tool to measure the effectiveness of the exercise program on spinal stiffness and it was proofed that physical exercises are an essential parameter of managing the disease and delaying the complications as the spine and joint stiffness.

This finding was supported by Gyurcsik et al., (2013) who mentioned in their study that, several subjective and practical criteria changed after three months of physical rehabilitation, including pain severity and spine stiffness. To sustain and improve spinal stability, retain functional capability, and reduce discomfort and stiffness, AS patients can be introduced to a complex, individualized physical therapy program. In this respect, Sveaas et al., (2021) stressed that individuals with Axial Spondyloarthritis, a 3-month exercise program has a significant longterm impact on leisure-time physical activity, suggesting an improved health profile. Also, Kjeken et al., (2013) found that, The Bath Ankylosing Spondylitis Metrology Index (BASMI) score, physical role, mental role, vitality, and bodily pain all improved statistically significantly after 4 months in the rehabilitation group.

The study also clarified that there was a statistically significant difference between the mean score of the health assessment questionnaire for spondyloarthropathies (post-test) and body mass index (BMI) of the studied sample. According to the researcher's opinion, patients with normal body weight could easily perform exercises and continue to perform them according to the prescribed schedule. While obese patients cannot perform the exercises regularly plus the effect of obesity on the pain and stiffness of the joints.

Finally, regarding the correlation between the mean score of BASMI, BASFI, and health assessment questionnaire for spondyloarthropathies of the studied sample, the present study revealed that there were positive correlations between BASFI \& health assessment (post-test), BASMI pre\& post-test, BASFI pre\& post-test, and Health assessment pre\& post-test. Regarding the researchers' view, the valuable effects of the exercise program were clear on decreasing the joint stiffness that helps to improve the physical functioning of patients such as (driving a car, using a rear-vision mirror, carrying heavy groceries, sitting for long periods, and working at a desk) that help the patients to perform daily tasks.

Khuman, (2018) found that the combination of supervised physiotherapy interventions and unsupervised home exercises had promising shortterm as well as long-term effects without deterioration in AS symptoms with increased patients' mobility and physical ability. Also, Seiler et al., (2020) illustrated that the key purpose of exercise therapy is to prevent patients from stiffening up in a flexed posture and to keep or enhance the functional ability. The long-term goal is to keep the posture in good condition.

\section{Conclusion:}

The study findings concluded that a three months specific exercise program has a great effect on patients with AS as there was a statistically significant difference between pre and post-test mean score of bath ankylosing spondylitis functional index, health assessment questionnaire for spondyloarthropathies, and bath ankylosing spondylitis metrology index which means that; the 
patient's physical functioning has been improved, patient's difficulty of performing the physical functioning has been decreased, and the patient's spinal column mobility (axial status) has been improved (decreased stiffness) after three months from the implementation of the exercise programs.

\section{Recommendations:}

- Applying the specific exercise program on the Ankylosing Spondylitis patients at different rehabilitation units to improve spinal and joint stiffness.

- Performing a new research to explore the relation between patients' compliance to the specific exercise program and improving their physical function and joint stiffness.

- Application of the research on larger sample and in different geographical areas.

\section{References:}

- Amarnani, R. \& Soni, A., (2020): The efficacy of biologic treatment in improving fatigue in ankylosing spondylitis: a literature review and implications for clinical practice. Rheumatology, 59(Supplement_2) P260.

- Bilberg, A., Sveaas, S., Dagfinrud, H. \& Mannerkorpi, K., (2020): How Do Patients With Axial Spondyloarthritis Experience High-Intensity Exercise?, ACR Open Rheumatology, Volume2, Issue4, Pages 207-213. https://onlinelibrary.wiley.com/doi/full/10.1002/ac r2.11128

- Calin A, Garrett S, Whitelock H, Kennedy LG, O'Hea J, Mallorie P, \& Jenkinson T, (1994): A new approach to defining functional ability in ankylosing spondylitis: the development of the Bath Ankylosing Spondylitis Functional Index. $J$ Rheumatol. 1994 Dec; 21(12):2281-5. PMID: 7699629.

- Conditions G., (2021): Ankylosing Spondylitis: Medlineplus Genetics. [online] Medlineplus.gov. Available https://medlineplus.gov/genetics/condition/ankylo sing-spondylitis/> [Accessed 22 January 2021].

- Daltroy LH, Larson MG, Roberts WN, \& Liang MH, (1990): A modification of the Health Assessment Questionnaire for spondyloarthropathies. J Rheumatology; 17:94650. https://pubmed.ncbi.nlm.nih.gov/2213762/

- Elia, D., (2018): Chronic Inflammatory Arthritis: Ankylosing Spondylitis. Spinal Diseases and Research, 1(1), pp.01-03.

- Fang, M., Wu, C., Weng, L. \& Huang, H., (2019): Factors associated with depressive symptoms in patients with ankylosing spondylitis in Northern Taiwan. PLOS ONE, 14(10), p.e0224298.

- Feintuch, S. (2021): Ankylosing Spondylitis Risk Factors: Here's What Causes Ankylosing Spondylitis. [online] CreakyJoints. Available at: <https://creakyjoints.org/education/ankylosingspondylitis-risk-factors/> [Accessed 2 March 2021].

- Firestein, G., Gabriel, S., McInnes, I. \& O'Dell, J., (2017): Kelley and Firestein's Textbook of Rheumatology. 10th. ed, Philadelphia, PA: Elsevier. Part. 10, Ch. 75, p. 1264.

- Fongen, C., Halvorsen, S. \& Dagfinrud, H., (2013): High disease activity is related to low levels of physical activity in patients with ankylosing spondylitis. Clinical Rheumatology, 32(12), pp.1719-1725.

- Gossec, L., Guyard, F., Leroy, D., Lafargue, T., Seiler, M., Jacquemin, C., Molto, A., Sellam, J., Foltz, V., Gandjbakhch, F., Hudry, C., Mitrovic, S., Fautrel, B. \& Servy, H., (2019): Detection of Flares by Decrease in Physical Activity, Collected Using Wearable Activity Trackers in Rheumatoid Arthritis or Axial Spondyloarthritis: An Application of Machine Learning Analyses in Rheumatology. Arthritis Care \& Research, 71(10), pp.1336-1343.

- Gyurcsik, Z., Bodnár, N., Szekanecz, Z. \& Szántó, S., (2013): Treatment of ankylosing spondylitis with biologics and targeted physical therapy. Zeitschrift für Rheumatologie, 72(10), pp.997-1004.

- Hollick, R., Dean, L., Shim, J., Jones, G. \& Macfarlane, G., (2019): The impact of axial spondyloarthritis on work productivity in individuals living in rural areas: results from the British Society for Rheumatology Biologics Register for Ankylosing Spondylitis (BSRBRAS). Rheumatology, 58(Supplement_3).

- Jenkinson TR, Mallorie PA, Whitelock HC, Kennedy LG, Garrett SL, \& Calin A. (1994): Defining spinal mobility in ankylosing spondylitis (AS). The Bath AS Metrology Index. $J$ Rheumatology; 21:1694-8. https://pubmed.ncbi.nlm.nih.gov/7799351/

- Jin, J., Wang, Y. \& Deng, Z., (2017): Increased risk of diabetes in inflammatory orthopedics diseases. AME Medical Journal, 2, pp.71-71.

- Johns Hopkins Arthritis Center. (2021): Ankylosing Spondylitis: Symptoms, Diagnosis, and Treatment. [online] Available at: $<$ https://www.hopkinsarthritis.org/arthritisinfo/ankylosing-spondylitis/> [Accessed 2 March 2021].

- Jung, S., Park, J. \& Johnson, J., (2019): Training effects of Dahn Taekwondo's 
Spondylitis Improvement Program on ankylosing spondylitis: a case study. Physical Activity Review, 7, pp.219-233.

- Khuman, R., (2018): Long-term effectiveness of physiotherapy in a case of ankylosing spondylitis. Physiotherapy - The Journal of Indian Association of Physiotherapists, 12(2), p.88.DOI: 10.4103/pjiap.pjiap_24_18https://www.pjiap.org/a rticle.asp?issn=0973-

6549 ; year $=2018$; volume $=12 ;$ issue $=2 ;$ spage $=88$;ep age $=92$; aulast $=$ Khuman

- Kjeken, I., RÃ̄nningen, A., Spada, C., Mowinckel, P., Hagen, K. \& Dagfinrud, H., (2013): A three-week multidisciplinary in-patient rehabilitation program had positive long-term effects in patients with ankylosing spondylitis: Randomized controlled trial. Journal of Rehabilitation Medicine, 45(3), pp.260-267.

- Lee, Y. \& Song, G., (2019): Diabetes mellitus in ankylosing spondylitis. Ann Rheum Dis;annrheumdis-2019-216335. doi: 10.1136/annrheumdis-2019-216335.

- Liang, H., Tian, X., Liu, X., Wang, S., Dai, Y., Kang, L., Chen, L. \& Jin, L., (2018): The comparative efficacy of group- versus home-based exercise programs in patients with ankylosing spondylitis. Medicine, 97(29), p.e11540.

- Liang, H., Zhang, H., Ji, H. \& Wang, C., (2015): Effects of a home-based exercise intervention on health-related quality of life for patients with ankylosing spondylitis: a metaanalysis. Clinical Rheumatology, 34(10), pp.17371744.

- Millner, J., Barron, J., Beinke, K., Butterworth, R., Chasle, B., Dutton, L., Lewington, M., Lim, E., Morley, T., O'Reilly, J., Pickering, K., Winzenberg, T. \& Zochling, J., (2016): Exercise for ankylosing spondylitis: An evidence-based consensus statement. Seminars in Arthritis and Rheumatism, 45(4), pp.411-427.

- Naqvi, E., (2021): Risk Factors of Ankylosing Spondylitis. [online] Ankylosing Spondylitis News. Available at: $<$ https://ankylosingspondylitisnews.com/riskfactors-of-ankylosing-spondylitis/> [Accessed 2 March 2021].

- Pécourneau, V., Degboé, Y., Barnetche, T., Cantagrel, A., Constantin, A. \& RuyssenWitrand, A., (2018): Effectiveness of Exercise Programs in Ankylosing Spondylitis: A MetaAnalysis of Randomized Controlled Trials. Archives of Physical Medicine and Rehabilitation, 99(2), pp.383-389.e1.

- Physiopedia. (2021): Ankylosing Spondylitis (Axial Spondyloarthritis). [online] Available at: <https://www.physio-
pedia.com/Ankylosing_Spondylitis_(Axial_Spond yloarthritis)> [Accessed 22 January 2021].

- Regnaux, J., Davergne, T., Palazzo, C., Roren, A., Rannou, F., Boutron, I. \& Lefevre-Colau, M., (2019): Exercise programs for ankylosing spondylitis. Cochrane Database of Systematic Reviews, (10): CD011321. DOI: 10.1002/14651858.CD011321.PMCID: PMC6774 752.https://www.ncbi.nlm.nih.gov/pmc/articles/P MC6774752/

- Rouse, P., Standage, M. \& Sengupta, R., (2019): Living with ankylosing spondylitis: an open response survey exploring physical activity experiences. Rheumatology Advances in Practice, 3(2).

- Seiler, M., Vermeylen, B., Poortmans, B., Feipel, V. \& Dugailly, P., (2020): Effects of nonmanipulative osteopathic management in addition to physical therapy and rehabilitation on clinical outcomes of ankylosing spondylitis patients: A preliminary randomized clinical trial. Journal of Bodywork and Movement Therapies, 24(4), pp.51-56.

- Sveaas, S., Dagfinrud, H., Johansen, M., Pedersen, E., Wold, O. \& Bilberg, A., (2019): Longterm Effect on Leisure Time Physical Activity Level in Individuals with Axial Spondyloarthritis: Secondary Analysis of a Randomized Controlled Trial. The Journal of Rheumatology, 47(8), pp.1189-1197.DOI: https://doi.org/10.3899/jrheum.190317

- Wang, R. \& Ward, M., (2018): Epidemiology of axial spondyloarthritis. Current Opinion in Rheumatology, 30(2), pp.137-143.

- Wenker, K. \& Quint, J., (2021): Ankylosing Spondylitis. [online] Ncbi.nlm.nih.gov. Available at:

<https://www.ncbi.nlm.nih.gov/books/NBK47017 3/> [Accessed 22 January 2021].

- Yazici, A., Ozdemir Isik, O., Temiz Karadag, D. \& Cefle, A., (2020): Are there any clinical differences between ankylosing spondylitis patients and familial Mediterranean fever patients with ankylosing spondylitis? International Journal of Clinical Practice, 75(1). 